\title{
Endoscopic Submucosal Dissection of Gastric Adenocarcinoma Involving the Pylorus Circumference
}

\author{
Liliana Carvalho Pedro Barreiro Cristina Chagas \\ Gastroenterology Department of Hospital Egas Moniz, Centro Hospitalar de Lisboa Ocidental, Lisbon, Portugal
}

Keywords

Gastric adenocarcinoma · Pylorus - Endoscopic submucosal dissection

\section{Disseção Endoscópica da Submucosa por Adenocarcinoma Gástrico Envolvendo a Circunferência do Piloro}

\section{Palavras Chave}

Adenocarcinoma gástrico · Piloro · Disseção endoscópica da submucosa

An 82-year-old Caucasian woman with multiple comorbidities was undergoing endoscopic surveillance at our department for post-endoscopic curative resection of intramucosal adenocarcinoma of the gastric antrum. A follow-up upper endoscopy showed a superficial pyloric lesion (0-IIa+IIc, according to the Paris classification) located mainly in the bulbar segment and involving about $2 / 3$ of the pylorus circumference. A narrow band imaging (Olympus ${ }^{\circledR}$ ) study revealed loss of both crypts and vascular pattern (Fig. 1). The multidisci-

\section{KARGER}

E-Mail karger@karger.com www.karger.com/pjg
(C) 2017 Sociedade Portuguesa de Gastrenterologia Published by S. Karger AG, Basel

Karcer Open access

This article is licensed under the Creative Commons AttributionNonCommercial-NoDerivatives 4.0 International License (CC BYNC-ND) (http://www.karger.com/Services/OpenAccessLicense) Usage and distribution for commercial purposes as well as any distribution of modified material requires written permission. plinary assessment suggested an endoscopic resection by endoscopic submucosal dissection (ESD) technique. The procedure was then performed under general anaesthesia using the ERBE ICC electrosurgical generator with Flush Knife (Fujifilm ${ }^{\circledR}$ ) and IT knife nano (Olympus $\left.^{\circledR}\right)$. Carbon dioxide was used for insufflation. At first, small coagulation marks were made $2-5 \mathrm{~mm}$ around the lesion. Then, a sufficient lifting was obtained with submucosal solution injection of Voluven ${ }^{\circledR}$, indigo carmine

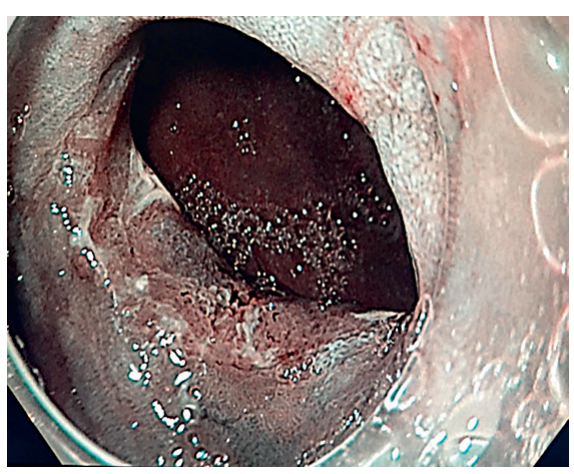

Fig. 1. Lesion involving about $2 / 3$ of the pylorus circumference and located mainly in the bulbar segment; loss of crypts and vascular pattern at narrow band imaging study.
Dr. Liliana Carvalho

Gastroenterology Department of Hospital Egas Moniz Centro Hospitalar de Lisboa Ocidental

Rua Da Junqueira 126, PT-1349-019 Lisbon (Portugal)

E-Mail lilipcarvalho@gmail.com 


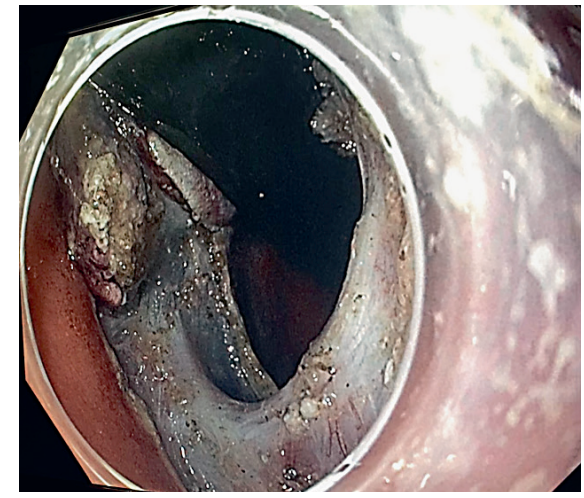

Fig. 2. Retroflexion position was the main technical approach in the bulb.

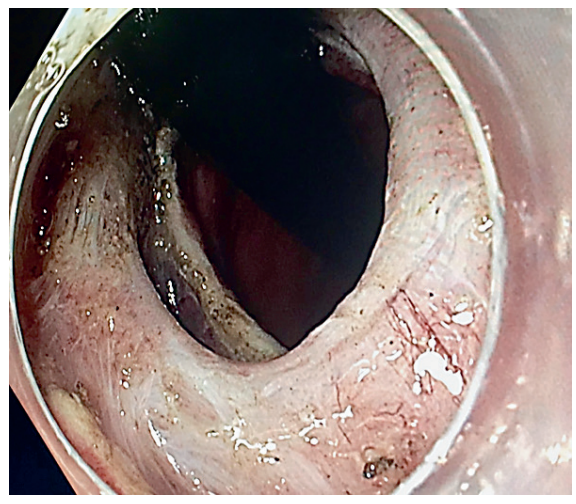

Fig. 3. Artificial ulcer showed the entire pylorus muscle ring.

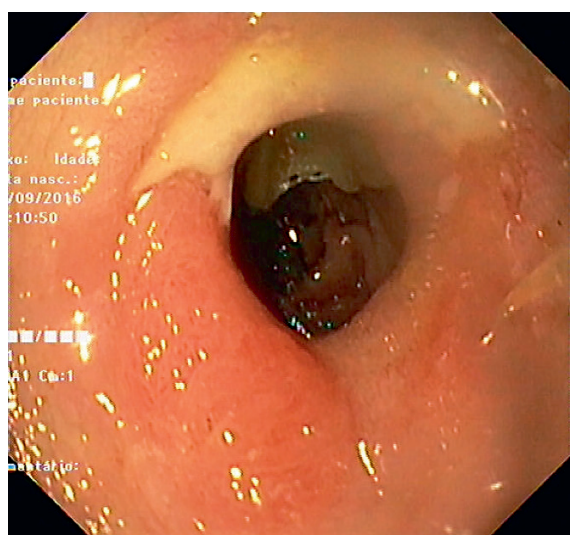

Fig. 4. Pylorus scar at the first follow-up, 3 months later. and epinephrine (1:250,000). ENDO CUT Mode was used for mucosal incision, forced coagulation for submucosal dissection and soft coagulation for haemostasis. Due to lesion size and location, the retroflexion position was the main technical approach in the bulb (Fig. 2), achieving complete and en block excision. In the subsequent artificial ulcer, comprising the whole circumference of the pylorus, it was possible to identify the entire pylorus muscle ring (Fig. 3). There were no complications. Histology revealed a moderately differentiated intramucosal adenocarcinoma that was fully excised (R0) with no lymphovascular invasion or ulceration. To minimize the risk of late pyloric stenosis, she empirically underwent oral corticosteroid therapy (30 $\mathrm{mg}$ of prednisolone per day), which was then tapered gradually (5 mg per week). The patient was discharged $48 \mathrm{~h}$ later without complaints. On endoscopic revaluation, 3 months later, no residual lesion or pyloric stenosis was documented (Fig. 4).

ESD is currently recognized as the treatment of choice for resection of most gastric superficial neoplastic lesions defined as early gastric cancer (EGC) [1]. It allows high rates of curative resection with a good safety profile, preserving the stomach's integrity, allowing a better quality of life when compared to alternative therapies, even in potentially high-risk patients [2]. In the last 2 decades, with the development of ESD, a revolution in the treatment of EGC was achieved [1]. The possibility of en bloc endoscopic resection (94 and 95\% reported in 2 single Portuguese centres), regardless of lesion size, has made ESD the favourite minimally invasive treatment for EGC $[3,4]$. A recent systematic review documented a lower morbidity for ESD and a similar 5-year survival compared to surgery [5].

However, therapies for lesions involving the pylorus are technically more difficult, resulting in a poorer outcome overall, considering rates of complete resection (58-79\%), bleeding (8\%), perforation (1\%) and stenosis (1\%), especially for larger lesion spreading over more than $50 \%$ of the pylorus circumference and for those with predominant duodenal expression [6].

Metachronous gastric lesions are the main concern after a curative endoscopic resection, and the patients should be at regular endoscopic surveillance, probably every year and even more often than 5 years after ESD for EGC [4].

\section{Statement of Ethics}

This report has been performed in accordance with the principles of the Helsinki Declaration in order to protect patient confidentiality.

\section{Disclosure Statement}

To the best of our knowledge, no conflict of interest, financial or other, exists. 


\section{References}

1 Pimentel-Nunes P, Dinis-Ribeiro M, Ponchon T, Repici A, Vieth M, De Ceglie A, et al: Endoscopic submucosal dissection: European Society of Gastrointestinal Endoscopy (ESGE) Guideline. Endoscopy 2015;47:829854.

2 Pimentel-Nunes P, Libânio D, Dinis-Ribeiro $\mathrm{M}$ : Evaluation and management of gastric superficial neoplastic lesions. GE Port J Gastroenterol 2017;24:8-21.
3 Rodrigues J, Carmo J, Carvalho L, Barreiro P, Chagas C: Endoscopic submucosal dissection for gastrointestinal superficial lesions: initial experience in a single Portuguese center. GE Port J Gastroenterol 2015;22:190-197.

4 Libânio D, Pimentel-Nunes P, Afonso LP, Henrique R, Dinis-Ribeiro M: Long-term outcomes of gastric endoscopic submucosal dissection: focus on metachronous and noncurative resection management. GE Port J Gastroenterol 2017;24:31-39.
5 Kondo A, Moura E, Bernardo W, Yagi O, Moura D, Moura E, et al: Endoscopy vs surgery in the treatment of early gastric cancer: systematic review. World J Gastroenterol 2015;21:13177-13187.

6 Bae JH, Kim GH, Lee BE, Kim TK, Park DY, Song GA: Factors associated with the outcomes of endoscopic submucosal dissection in pyloric neoplasms. Gastrointest Endosc 2015;81:303-311. 